\title{
Genetic Differences between Physical Injury Patients With and Without Post-traumatic Syndrome: Focus on Secondary Findings and Potential Variants Revealed by Whole Exome Sequencing
}

\author{
Hee-Ju Kang ${ }^{1, *}$, Ho-Yeon Lee, ${ }^{2,3} *$, Ki-Tae Kim ${ }^{4}$, Ju-Wan Kim', Ju-Yeon Lee', Sung-Wan Kim', Jung-Chul Kim ${ }^{5}$, \\ Il-Seon Shin ${ }^{1}$, Namshin Kim ${ }^{2,3}$, Jae-Min Kim ${ }^{1}$ \\ ${ }^{1}$ Department of Psychiatry, Chonnam National University Medical School, Gwangju, ${ }^{2}$ Department of Bioinformatics, Korea Research Institute \\ of Bioscience and Biotechnology School of Bioscience, University of Science and Technology (UST), ${ }^{3}$ Genome Editing Research Center, Korea \\ Research Institute of Bioscience and Biotechnology, Daejeon, ${ }^{4}$ Department of Laboratory Medicine, Korea University Anam Hospital, Seoul, \\ ${ }^{5}$ Trauma Center, Department of Surgery, Chonnam National University Medical School, Gwangju, Korea
}

Objective: Sudden traumatic physical injuries often cause psychological distress, which may be associated with chronic disability. Although considerable effort has been expended to identify genetic predictors of post-traumatic stress disorder (PTSD) after traumatic events, genetic predictors of psychological distress in response to severe physical injuries have been yet to be elucidated using whole exome sequencing (WES). Here, the genetic architecture of post-traumatic syndrome (PTS), which encompasses a broad range of psychiatric disorders after traumatic events including depression, anxiety disorder, acute stress disorder, and PTSD, was explored using WES in severely physically injured patients, focusing on secondary findings and potential PTS-related variants.

Methods: In total, 141 severely physically injured patients were consecutively recruited, and PTS was evaluated within 1 month of the injury. Secondary findings were analyzed according to PTS status. To identify PTS-related variants, genome-wide association analyses and the optimal sequencing kernel association test were performed.

Results: Of the 141 patients, 88 (62\%) experienced PTS. There were 108 disease-causing variants in severely physically injured patients. As secondary findings, the stress- and inflammation-related signaling pathways were enriched in the PTS patients, while the glucose metabolism pathway was enriched in those without PTS. However, no significant PTS-related variants were identified.

Conclusion: Our findings suggest that genetic alterations in stress and inflammatory pathways might increase the likelihood of PTS immediately after severe physical injury. Future studies with larger samples and longitudinal designs are needed.

KEY WORDS: Stress disorders, traumatic; Genetics; Whole exome sequencing; Incidental findings; Accidental injuries.

Received: September 7, 2020 / Revised: October 22, 2020

Accepted: October 26, 2020

Address for correspondence: Jae-Min Kim

Department of Psychiatry, Chonnam National University Medical

School, 160 Baekseo-ro, Dong-gu, Gwangju 61469, Korea

E-mail: jmkim@chonnam.ac.kr

ORCID: https://orcid.org/0000-0001-7409-6306

Namshin Kim

Genome Editing Research Center, Korea Research Institute of Bioscience and Biotechnology, 125 Gwahak-ro, Yuseong-gu,

Daejeon 34141, Korea

E-mail: deepreds@kribb.re.kr

ORCID: https://orcid.org/0000-0001-6361-274X

*These authors contributed equally to this study as co-first authors.

\section{INTRODUCTION}

Traumatic physical injuries affect millions of people every year and are projected to have the third leading cause of disease burden in 2020. Patients with physical injuries often experience various psychological distresses such as depression, anxiety, acute stress disorder (ASD), and posttraumatic stress disorder (PTSD) [1,2], which can persist in cases of long-term disability [3]. Among these, previous studies demonstrated that genetic factors accounted for $40-50 \%$ of the variance in PTSD following trauma [4]. Thus, considerable effort has been expended to identify genetic markers of PTSD, to identify patients at risk of

(c) This is an Open-Access article distributed under the terms of the Creative Commons Attribution Non-Commercial License (http://creativecommons.org/licenses/by-nc/4.0) which permits unrestricted non-commercial use, distribution, and reproduction in any medium, provided the original work is properly cited. 
chronic distress and disability [5,6]. Most of these studies were genome-wide association studies (GWAS) in chronic PTSD patients [6]. However, genetic markers for PTSD remain to be clearly established with consistent replication across various study projects, and the pathophysiological mechanisms underlying PTSD onset have yet to be elucidated.

PTSD is often accompanied by other psychiatric conditions, such as major depression and anxiety disorders $[7,8]$. Additionally, patients exhibiting severe depression and anxiety symptoms immediately after trauma were more likely to develop PTSD later [9]. Therefore, it is important to examine the genetic architecture of depression, anxiety, and ASD in subjects suffering from these various psychological conditions immediately after traumatic events, to allow early identification of high-risk individuals. Against this background, we aimed to evaluate the genetic architecture of the newly defined post-traumatic syndrome (PTS), which encompasses a broad range of psychiatric disorders that often occur after severe traumatic physical injury, including depression, anxiety disorder, ASD, and PTSD. Given the limited nature of the GWAS findings regarding post-traumatic stress-related symptoms, whole exome sequencing (WES) data from patients with severe physical injury were analyzed in this study. GWAS have uncovered thousands of common variants among which those with a low impact and high frequency are associated with the occurrence of complex diseases including PTS [10]. However, the majority of the variants thus identified are located in intronic regions, and extensive fine mapping and functional validation is needed to identify the causal genes [11]. Variants reaching a genome-wide significance in GWAS accounted for only a small portion of the heritability [12]. WES allows investigation of the full spectrum of genetic variants including both common and rare ones by sequencing the entire protein coding region of genes that harbor about $85 \%$ of human mutations [13]. Recently, to understand the genetic basis of complex diseases, including psychiatric disorders, investigation of rare variants was encouraged based on the heterogeneity of such diseases [13]. In this regard, WES which provides a comprehensive catalog of clinically significant genetic variants can serve as an alternative to GWAS. WES provides information about variants over and above that which it was originally intended to uncover. In this study, secondary findings refer to var- iants with known or potentially pathogenicity unrelated to the primary disease. To understand the genetic architecture underlying PTS, this study investigated secondary findings according to PTS status, and also sought to identify genetic markers of PTS.

\section{METHODS}

\section{Study Population and Psychiatric Assessments}

The present analyses were conducted as part of a 2-year prospective study that designed a biomarker-based diagnostic algorithm for post-traumatic syndrome (BioPTS) for application to patients who experienced a traumatic event, such as a severe physical injury [14]. The participants were consecutively recruited from among patients recently hospitalized for a severe physical injury (Injury Severity Score $\geq 11$ ) [15] at the Trauma Center of Chonnam National University Hospital, Gwangju, Korea. The baseline data of the participants who were eligible for the BioPTS study [14] and agreed to participate in the study were included in the present analyses. Written informed consent for the BioPTS study was obtained; the BioPTS study was approved by the Chonnam National University Hospital Institutional Review Board (CNUH-2015-148).

The psychiatric status of the participants was assessed within 1 month of the physical injury. PTS was considered present when patients experienced at least one of three conditions after the injury: depression, anxiety disorder, or post-traumatic stress disorder. The Mini International Neuropsychiatric Interview (MINI) and Clinician-administered PTSD Scale for DSM-5 (CAPS-5) [16] were used to diagnose depression, anxiety disorder, and PTSD $[17,18]$. The severity of PTS symptoms including depression, anxiety, and PTSD was measured using the Hamilton Rating Scale for Depression (HAMD) [19], the Hospital Anxiety and Depression Scale (HADS) [20], the Hamilton Anxiety Rating Scale (HAMA) [21], and the Impact Event ScaleRevised (IES-R) [22].

Secondary findings were privately disclosed to participants who wished to know the results, by medical geneticist and a genetic counselor. The clinical significance of the findings was discussed, and documents including variant information and relevant resources were provided. Secondary findings were not added to the participants' medical records, and no formal referrals to relevant specialists were made except when participants agreed to 
share their results with their healthcare providers.

\section{Whole Exome Sequencing}

WES was performed on venous blood from participants in the BioPTS study who consented to genetic testing, to analyze the coding sequence region of the entire genome using the Illumina HiSeq2500 sequencer (Illumina, Inc., San Diego, CA, USA) with the standard protocol of the manufacturer. SureSelectHuman All Exon V5+UTR probe set that included the 359,555 exons of 21,522 genes were used and the size of the total targeted region was $75 \mathrm{Mb}$. For the generation of standard exome capture libraries, Agilent SureSelect Target Enrichment protocol for Illumina paired-end sequencing library (ver. B.3, June 2015) was used.

After quality control using FastQC, WES reads were mapped to the human genome reference (hg38/GRCh38) using the Burrows-Wheeler Aligner (BWA; version 0.7.12), which provided data in BAM format [23]. Then, PCR duplicates were removed using Picard tools (version 1.134; http://broadinstitute.github.io/picard/). Local realignment around indels, base call quality score recalibration (BQSR), and reduced reads were carried out using the Genome Analysis Toolkit (GATK; version 3.6) [24]. Variant genotyping for each sample was performed with GATK HaplotypeCaller. Variant sites were filtered using variant quality score recalibration [25]. Heterozygous genotypes were excluded if they did not have at least five alternate allele reads. Variants were filtered based on minor allele frequency (MAF) using the Genome Aggregation Database (GnomAD; https://gnomad.broadinstitute.org/), Korean Variants Archive (KOVA) [26], and Korean Reference Genome (KRG; http://www.cdc.go.kr/contents.es?mid= a50303020400) databases. In the secondary finding analyses, variants were filtered based on a MAF cutoff of 0.01 ; the sequencing coverage of 59 genes of interest is detailed in Supplementary Table 1 (available online). Through the analysis of PTS-related variants, a final list of variants was generated after removing subjects and single nucleotide polymorphisms (SNPs) with excessive missingness. The criteria in missingness of SNPs and individuals were 0.1 and 0.3 , respectively.

\section{Statistical Analyses}

Baseline characteristics including age, sex, and the severity of psychiatric symptoms were analyzed for the en- tire sample, and were also compared between the PTS and non-PTS groups using $t$ tests or chi-square $\left(\chi^{2}\right)$ tests, as appropriate. The secondary findings were also analyzed by PTS status. All statistical analyses were performed using SPSS (version 23.0; IBM Corp., Armonk, NY, USA) and R software (version 3.5.3; http://www.r-project.org/). The overall analysis procedure is illustrated in Figure 1.

\section{Analysis of secondary findings}

In this study, secondary findings refers to genomic variants of potential clinical interest that are unrelated to the primary reason for testing. For the analysis of secondary findings, disease-causing variants were identified including 59 actionable genes that was proposed to be related to pathogenic or likely pathogenic variants associated with 24 medical conditions by the American College of Medical Genetics (ACMG) [27]. These disease-causing variants in BioPTS participants were annotated using ClinVar [28] and classified as pathogenic (P), likely pathogenic (LP), "uncertain significance", likely benign, or benign. Only the $P$ and LP variants were included in the present analyses. Variants and genes listed in the Human Gene Mutation Database (HGMD) [29] were added to the annotations to cover the variant information missing from the ClinVar database. The HGMD contains information on inherited diseases associated with germline mutations in a human nuclear gene, which have been validated in the literature [29]. Among the six classes of variants, "disease-causing mutation (DM)" and "disease causing mutations? (DM?)," which correspond to the $\mathrm{P}$ and LP ACMG categories, respectively, were included in the present analyses. The final list of secondary findings included the variants identified by either ClinVar or HGMD. To reduce the number of false-positive variants, any variants that were annotated inconsistently by ClinVar and HGMD, or were classified as uncertain significance, were reviewed in terms of whether they had previously been reported to be related to disease; such variants were also included in the final list. The 59 variants recommended by the ACMG were validated by independent investigators via Sanger sequencing of the WES findings. The results were then provided to the participants.

Ingenuity Pathway Analysis (IPA; Qiagen, Hilden, Germany) [30] was used for pathway enrichment analysis of canonical pathways according to PTS status. Variants 


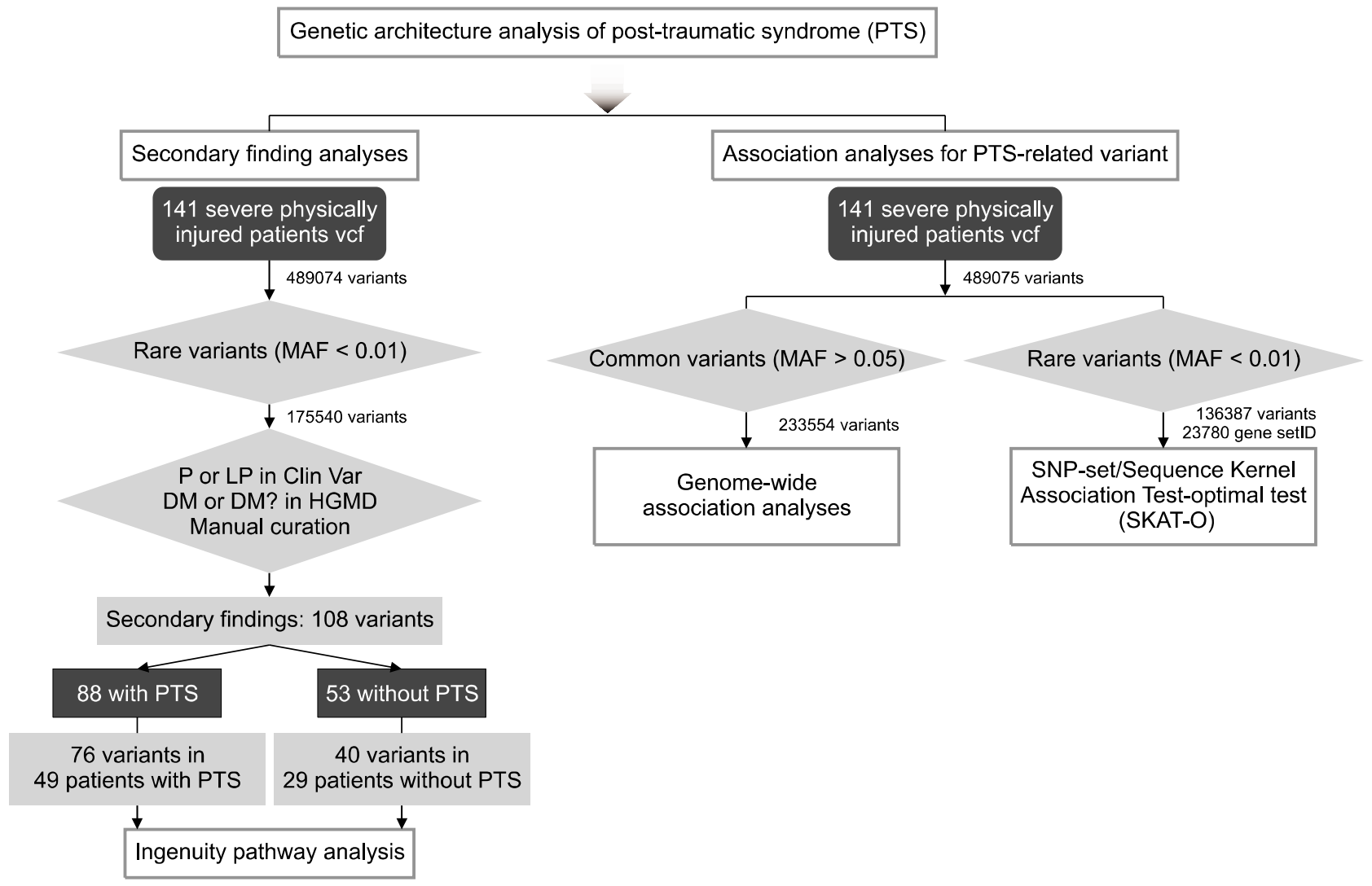

Fig. 1. Outline of analytic process.

VCF, variant call format; MAF, minor allele frequency; P, pathogenic; LP, likely pathogenic; DM, disease-causing mutation; DM? disease-causing mutation?; HGMD, Human Gene Mutation Database.

identified as being related to secondary findings were mapped to genes based on their location within a 20-kb region of the 5' and 3' ends of the first and last exons. Fisher's exact test was used to determine the probability that genes of interest were enriched in a specific canonical pathway more than would be expected by chance alone. An adjusted false discovery rate (FDR) $<0.05$ was considered significant.

\section{Analysis of PTS-related variants}

To identify genetic markers of PTS status immediately after severe traumatic injury, the associations of SNPs (MAF > 0.05) with PTS status were tested by logistic regression using PLINK software (version1.90b; https://www. cog-genomics.org/plink/). Individuals with the minor allele homozygous genotype constituted the reference group. A log-additive model of SNPs was devised with adjustment for clinical variables associated with the presence of PTS. Odds ratios and 95\% confidence intervals were calculated. Additional analyses were performed to account for the effect of rare variants $(\mathrm{MAF}<0.01)$ identified by WES analyses. The proportion of rare variant carriers was compared between the PTS and non-PTS groups using the optimal sequencing kernel association (SKAT-O) test [31] in the R package SKAT. As indicated in Figure 1, statistical significance was adjusted for multiple comparisons, as follows: 0.05/number of common variants analyzed $(23,354)$ and $0.05 /$ number of gene sets including rare variants $(23,780)$.

\section{RESULTS}

In total, 141 patients with severe physical injuries agreed to participate in the BioPTS study, and to provide blood samples for the genetic study. Of those patients, 88 (62\%) experienced at least one symptom of PTS. The mean time elapsed between the physical injury and assessment was $7.3 \pm 5.1$ days (range: $1-27$ days). The characteristics of the participants are summarized in Table 1. Severely injured patients with PTS were more 
Table 1. Demographic and clinical characteristics of participants

\begin{tabular}{|c|c|c|c|c|}
\hline Variables & Total $(n=141)$ & No PTS $(n=53)$ & PTS $(n=88)$ & $p$ value \\
\hline \multicolumn{5}{|l|}{ Socio-demographic characteristics } \\
\hline Age $(y r)$ & $55.0 \pm 17.0$ & $55.3 \pm 18.4$ & $53.7 \pm 16.0$ & 0.231 \\
\hline Sex, male & $92(65.2)$ & $41(77.4)$ & $51(58.0)$ & 0.019 \\
\hline \multicolumn{5}{|l|}{ Characteristics of injury } \\
\hline Injury severity score & $15.8 \pm 6.2$ & $14.6 \pm 6.3$ & $16.6 \pm 6.1$ & 0.063 \\
\hline Type of injury & & & & 0.257 \\
\hline Transport & $70(49.6)$ & $25(47.2)$ & $45(51.1)$ & \\
\hline Traumatic fall & $34(24.1)$ & $10(18.7)$ & $24(27.3)$ & \\
\hline Assaults & $3(2.1)$ & $2(3.8)$ & $1(1.1)$ & \\
\hline Blunt trauma: layed, compression, slip & $25(17.7)$ & $12(22.6)$ & $13(14.8)$ & \\
\hline Penetrating trauma & $6(4.2)$ & $3(5.7)$ & $3(3.4)$ & \\
\hline Others & $3(2.1)$ & $1(1.9)$ & $2(2.3)$ & \\
\hline \multicolumn{5}{|l|}{ Assessment scales } \\
\hline Hamilton depression rating scale & $8.9 \pm 6.9$ & $3.3 \pm 2.4$ & $12.2 \pm 6.3$ & $<0.001$ \\
\hline Hamilton anxiety rating scale & $6.4 \pm 6.7$ & $1.6 \pm 1.7$ & $9.3 \pm 6.9$ & $<0.001$ \\
\hline Hospital anxiety and depression scale & $11.9 \pm 9.3$ & $4.6 \pm 4.6$ & $16.3 \pm 8.5$ & $<0.001$ \\
\hline Impact event scale-revised & $11.6 \pm 12.9$ & $1.8 \pm 2.4$ & $17.6 \pm 13.0$ & $<0.001$ \\
\hline
\end{tabular}

Values are presented as mean \pm standard deviation or number $(\%)$.

PTS, posttraumatic syndrome.

likely to be female and to have experienced severe anxiety, depression, and PTSD, as measured by the HAMD, HAMA, HADS, and IES-R.

\section{Analyses of Secondary Findings}

A total of 108 disease-causing variants, in 6 of the 59 ACMG-recommended genes (KCNQ1, BRCA1, TNNI3, TNNT2, RYR2, and MYH7), were identified in the 141 severe physical injury patients (data not shown due to large burden of page but available upon request). Of the 108 variants, 76 disease-causing variants were found in 88 patients with PTS (86.4\%), while 40 variants were found in 53 patients without PTS (75.5\%) and 8 were found in both groups. Overall, 49 patients (55.7\%) with PTS had at least one disease-causing variant, whereas 29 patients (52.7\%) without PTS possessed disease-causing variants. The number of secondary findings was not significantly associated with PTS status ( $p$ value $=0.911$ ). Among the 59 ACMG-recommended genes, six variants $(4.3 \%)$ were found in the participants: four variants $(4.5 \%$; KCNQ1, $B R C A 1, T N N I 3$, and $M Y H 7$ ) were identified in patients with PTS, and two variants (3.8\%; TNNT2 and RYR2) were identified in patients without PTS. We validated the disease-causing variants for the six ACMG-recommended genes referred to above through Sanger sequencing.

IPA was used to identify associations of gene sets in the canonical pathway between patients with and without
PTS. Enrichment of genes in the paxillin, integrin, and MSP-RON signaling pathways, and of genes involved in DNA double-strand break repair by homologous recombination, DNA damage-induced 14-3-3 $\sigma$ signaling, chondroitin sulfate degradation, dermatan sulfate degradation, the DNA damage response (BRCA1), hereditary breast cancer signaling, and signaling in epithelial cells (GADD45 and aldosterone) were found to be enriched in severely injured patients with PTS (Table 2) [32-52]. Genes involved in glycogen degradation were only identified in severely injured patients without PTS.

\section{Analyses of PTS-related Variants}

To identify genes associated with PTS occurring immediately after severe traumatic injury, we conducted a GWAS analysis. None of the SNPs reached the threshold for genome-wide significance (Fig. 2A), but associations with $p$ values $<0.001$ are summarized in Table 3 . The SKAT-O test was performed on rare variants identified by WES, but none of those variants were significant (Fig. 2B).

\section{DISCUSSION}

Genetic characteristics that can differentiate patients with PTS from those without PTS were identified in this study. Patients who experienced PTS within 1 month after severe physical injury were more likely to have significant 
Table 2. Enrichment findings of secondary findings using ingenuity pathway analysis for canonical pathway (FDR $<0.05$ )

\begin{tabular}{|c|c|c|c|c|c|}
\hline $\begin{array}{c}\text { Ingenuity canonical } \\
\text { pathways }\end{array}$ & Function & Group & $\begin{array}{l}-\log (\mathrm{B}-\mathrm{H} \\
p \text { value })\end{array}$ & FDR & Molecules \\
\hline Paxillin signaling & $\begin{array}{l}\text { Paxillin is main component of focal adhesions and plays an important role in } \\
\text { the transduction of extracellular signals into intracellular responses. As a } \\
\text { scaffolding protein, paxillin contributes to the recruitment of specific kinases } \\
\text { and phosphatases, cofactors, oncoproteins and structural proteins involved } \\
\text { in intracellular signaling cascade. This pathway activation leads to } \\
\text { reorganization of the actin skeleton and the assembly/disassembly of focal } \\
\text { adhesion required for cell attachment, spreading and migration }[32,33]\end{array}$ & PTS & 1.35 & 0.045 & $\begin{array}{l}\text { ITGA2B, } \\
\text { PTPN11, } \\
\text { ITGB4, } \\
\text { ATM }\end{array}$ \\
\hline Integrin signaling & $\begin{array}{l}\text { The Integrin is a family of cell surface receptor that attach cells to the matrix } \\
\text { and mediate mechanical and chemical signals from it. These signals regulate } \\
\text { the activities of cytoplasmic kinases, growth factor receptors and ion } \\
\text { channels and control the organization of the intracellular actin cytoskeleton. } \\
\text { Thus, integrin signaling serve as master regulator of cell functions including } \\
\text { apoptosis, proliferation and differentiation [34]. In the brain, they are found } \\
\text { in neurons and glial cells and play essential roles in brain development and } \\
\text { function such as axon guidance, synaptogenesis, synaptic plasticity and } \\
\text { neuro-inflammation [35]. Many literatures showing the association between } \\
\text { integrin signaling pathway and neuropsychiatric disorders like depression } \\
\text { and dementia [36] }\end{array}$ & PTS & 1.35 & 0.045 & $\begin{array}{l}\text { ITGA2B, } \\
\text { PTPN11, } \\
\text { ITGB4, } \\
\text { TTN, } \\
\text { ATM }\end{array}$ \\
\hline $\begin{array}{l}\text { DNA double-strand } \\
\text { break repair by } \\
\text { homologous } \\
\text { recombination }\end{array}$ & $\begin{array}{l}\text { DNA double-strand breaks (DSB) are presumed to be the most deleterious } \\
\text { DNA lesions as they disrupt both DNA strands. Homologous recombination, } \\
\text { single-strand annealing, and non-homologous end-joining are considered to } \\
\text { be the pathways for repairing DSB [37] }\end{array}$ & PTS & 1.35 & 0.045 & $\begin{array}{l}\text { BRCA1, } \\
\text { ATM }\end{array}$ \\
\hline $\begin{array}{l}\text { Chondroitin sulfate } \\
\text { degradation } \\
\text { (metazoa) }\end{array}$ & $\begin{array}{l}\text { Chondroitin sulfate is a major component of connective tissue matrix (such as } \\
\text { skin and cartilage), but is also found on cell surface and basement } \\
\text { membranes and in intracellular granules of certain cells. Functions in matrix } \\
\text { locations are mainly structural, while functions in membranes are mainly as } \\
\text { receptors. Degradation of chondroitin sulfate is part of many processes. For } \\
\text { example, such degradation increases the permeability of connective tissues } \\
\text { and decreases the viscosity of body fluids. Although some of the enzymes } \\
\text { involved are circulated in the plasma, the general process of chondroitin } \\
\text { sulfate degradation generally takes place in the lysosome [38] }\end{array}$ & PTS & 1.35 & 0.045 & $\begin{array}{l}\text { HEXA, } \\
\text { CEMIP }\end{array}$ \\
\hline $\begin{array}{l}\text { Dermatan sulfate } \\
\text { degradation } \\
\text { (metazoa) }\end{array}$ & $\begin{array}{l}\text { Dermatan sulfate is expressed in many mammalian tissues and is the } \\
\text { predominant glycan present in the extracellular matrix of skin. Dermatan and } \\
\text { dermatan sulfate proteoglycans have also been implicated in cardiovascular } \\
\text { disease, tumorigenesis, infection, wound repair, and fibrosis. Within cells, } \\
\text { dermatan sulfate is degraded in two steps. The initial endohydrolysis is } \\
\text { followed by the sequential action of lysosomal exoenzymes to reduce the } \\
\text { resulting oligosaccharides to monosaccharides and inorganic sulfate [39] }\end{array}$ & PTS & 1.35 & 0.045 & $\begin{array}{l}\text { HEXA, } \\
\text { CEMIP }\end{array}$ \\
\hline $\begin{array}{l}\text { Hereditary breast } \\
\text { cancer signaling }\end{array}$ & $\begin{array}{l}\text { About } 8 \% \text { of breast cancer is hereditary. The signaling events that drive } \\
\text { hereditary breast cancer were included in this pathway (BRCA 1, BRCA2, } \\
\text { ATM, TP53, CHEK2, PTEN, CDH1, STK11, PALB2) [40] }\end{array}$ & PTS & 1.35 & 0.045 & $\begin{array}{l}\text { PTPN11, } \\
\text { BRCA1, } \\
\text { FANCA, } \\
\text { ATM }\end{array}$ \\
\hline $\begin{array}{l}\text { MSP-RON signaling } \\
\text { pathway }\end{array}$ & $\begin{array}{l}\text { Macrophage stimulating protein (MSP) is a hepatocyte growth factorlike protein } \\
\text { that mediates its functions via activating receptor tyrosine kinase recepteur } \\
\text { d'origine nantais (RON). MSP has also been shown to play a role in inducing } \\
\text { adhesion and motility of epithelial cells and attenuating apoptosis [41]. Thus } \\
\text { this signaling pathway protect BBB integrity [42]. Also MSP has been shown } \\
\text { to enhance complement mediated phagocytosis, induce macrophage arginase } \\
\text { activity, and regulate cytokines such as IL-12p70 and IFN- } \gamma \text { while RON receptor } \\
\text { tyrosine kinases (murine Stk), expressed on tissue-resident macrophages, } \\
\text { inhibit classical macrophage activation while promoting hallmarks of alter- } \\
\text { native activation, thus regulating the critical balance between the inflammatory } \\
\text { and wound-healing properties of activated macrophages [43]. Thus MSP-RON } \\
\text { Signaling Pathway is a class of key regulators of innate immune responses }\end{array}$ & PTS & 1.35 & 0.045 & $\begin{array}{l}\text { F11, } \\
\text { PTPN11, } \\
\text { ATM }\end{array}$ \\
\hline
\end{tabular}


Table 2. Continued

\begin{tabular}{|c|c|c|c|c|c|}
\hline $\begin{array}{c}\text { Ingenuity canonical } \\
\text { pathways }\end{array}$ & Function & Group & $\begin{array}{l}-\log (\mathrm{B}-\mathrm{H} \\
p \text { value })\end{array}$ & FDR & Molecules \\
\hline GADD45 signaling & $\begin{array}{l}\text { Gadd45 genes have been implicated in stress signaling in response to } \\
\text { physiological or environmental stressors, which results in cell cycle arrest, } \\
\text { DNA repair, cell survival and senescence, or apoptosis. Evidence } \\
\text { accumulated implies that Gadd45 proteins function as stress sensors is } \\
\text { mediated by a complex interplay of physical interactions with other cellular } \\
\text { proteins that are implicated in cell cycle regulation and the response of cells } \\
\text { to stress [44] }\end{array}$ & PTS & 1.35 & 0.045 & $\begin{array}{l}\text { BRCA1, } \\
\text { ATM }\end{array}$ \\
\hline $\begin{array}{l}\text { DNA damage-induced } \\
14-3-3 \sigma \text { signaling }\end{array}$ & $\begin{array}{l}14-3-3 \sigma \text { is a member of } 14-3-3 \text { family proteins that have critical roles in signal } \\
\text { transduction pathways and cell cycle regulation. } 14-3-3 \sigma \text { is the only } 14-3-3 \\
\text { isoform induced by tumor suppressor protein p53 in response to } \gamma \text { irradiation } \\
\text { and other DNA-damaging agents. } 14-3-3 \sigma \text { regulates the cell cycle by } \\
\text { interacting with cyclin-dependent kinases and serving as a target of p53 and } \\
\text { BRCA1 [45]. Thus, impairment in DNA damage-induced } 14-3-3 \sigma \text { Signaling } \\
\text { can make human epithelial cells grow indefinitely that may lead to tumor } \\
\text { formation [46] }\end{array}$ & PTS & 1.35 & 0.045 & $\begin{array}{l}\text { BRCA1, } \\
\text { ATM }\end{array}$ \\
\hline $\begin{array}{l}\text { Aldosterone signaling } \\
\text { in epithelial cells }\end{array}$ & $\begin{array}{l}\text { Aldosterone is one of primary adrenal cortical steroid hormone that act through } \\
\text { the mineralocorticoid receptor both in brain and in periphery. Aldosterone is } \\
\text { crucial for fluid, electrolyte, and hemodynamic homeostasis and regulation } \\
\text { of sympathetic drive, tissue repair and modulation of circulating inflammatory } \\
\text { cytokines [47]. With these mechanism, the aldosterone pathway suggested to } \\
\text { be related to depression and anxiety [48] }\end{array}$ & PTS & 1.32 & 0.045 & $\begin{array}{l}\text { SACS, } \\
\text { PTPN11, } \\
\text { SLC12A } \\
\text { 1, } \\
\text { ATM }\end{array}$ \\
\hline $\begin{array}{l}\text { Role of } B R C A 1 \text { in } \\
\text { DNA damage } \\
\text { response }\end{array}$ & $\begin{array}{l}\text { To cope with threats of numerous environmental hazards that induce various } \\
\text { kinds of DNA damage, a DNA damage response system has been established } \\
\text { to sense and repair DNA lesions in cells. Loss of this DNA damage response } \\
\text { triggers genomic instability, and ultimately promotes tumorigenesis. Thus, many } \\
\text { DNA damage response proteins are important tumor suppressors. BRCA is a } \\
\text { breast and ovarian cancer suppressor [49]. Accumulated evidence suggests } \\
\text { that } B R C A \text { plays important roles in several biological events during the DNA } \\
\text { damage response including cell cycle checkpoint activation and repair of } \\
\text { DNA double-strand breaks [50,51] }\end{array}$ & PTS & 1.32 & 0.045 & $\begin{array}{l}\text { BRCA1, } \\
\text { FANCA, } \\
\text { ATM }\end{array}$ \\
\hline $\begin{array}{l}\text { Glycogen } \\
\text { degradation III }\end{array}$ & $\begin{array}{l}\text { Glycogen degradation consists of three steps: (1) the release of glucose 1-phosphate } \\
\text { from glycogen, (2) the remodeling of the glycogen substrate to permit further } \\
\text { degradation, and (3) the conversion of glucose 1-phosphate into glucose } \\
\text { 6-phosphate for further metabolism. The glucose 6-phosphate derived from } \\
\text { the breakdown of glycogen has three fates: (1) It is the initial substrate for } \\
\text { glycolysis, (2) it can be processed by the pentose phosphate pathway to yield } \\
\text { NADPH and ribose derivatives; and (3) it can be converted into free glucose } \\
\text { for release into the bloodstream. This conversion takes place mainly in the } \\
\text { liver and to a lesser extent in the intestines and kidneys [52] }\end{array}$ & No-PTS & 1.48 & 0.033 & $\begin{array}{c}P Y G M \\
G A A\end{array}$ \\
\hline
\end{tabular}

FDR, false discovery rate; PTS, posttraumatic syndrome.

secondary findings in pathways related to stress and inflammatory reaction, whereas patients who did not suffer from PTS had significant secondary findings in the glucose metabolism pathway. No genetic variant (common or rare) was shown to be associated with PTS status due to the small sample size.

This is the first study to evaluate the genetic architecture of PTS using WES data in severely physically injured patients. A number of WES studies have reported secondary findings, with prevalence rates of $0.3-1.2 \%$ for individuals of African ancestry [53,54], $0.7-8.8 \%$ for those of European and American ancestry [54-56], and 1.6$21 \%$ for those of Asian ancestry [57-59]. In our Korean population of physically injured patients, six variants $(4.3 \%)$ based on the 59 ACMG-recommended genes were found which was similar prevalence to previous findings in Asian population. However, 108 variants (76.6\%) identified in the present study based on all counts of disease-causing variants was very different from previous studies. The differences in rates of significant secondary findings among populations might be due to differences in variant classification methods, a lack of non-Caucasian 

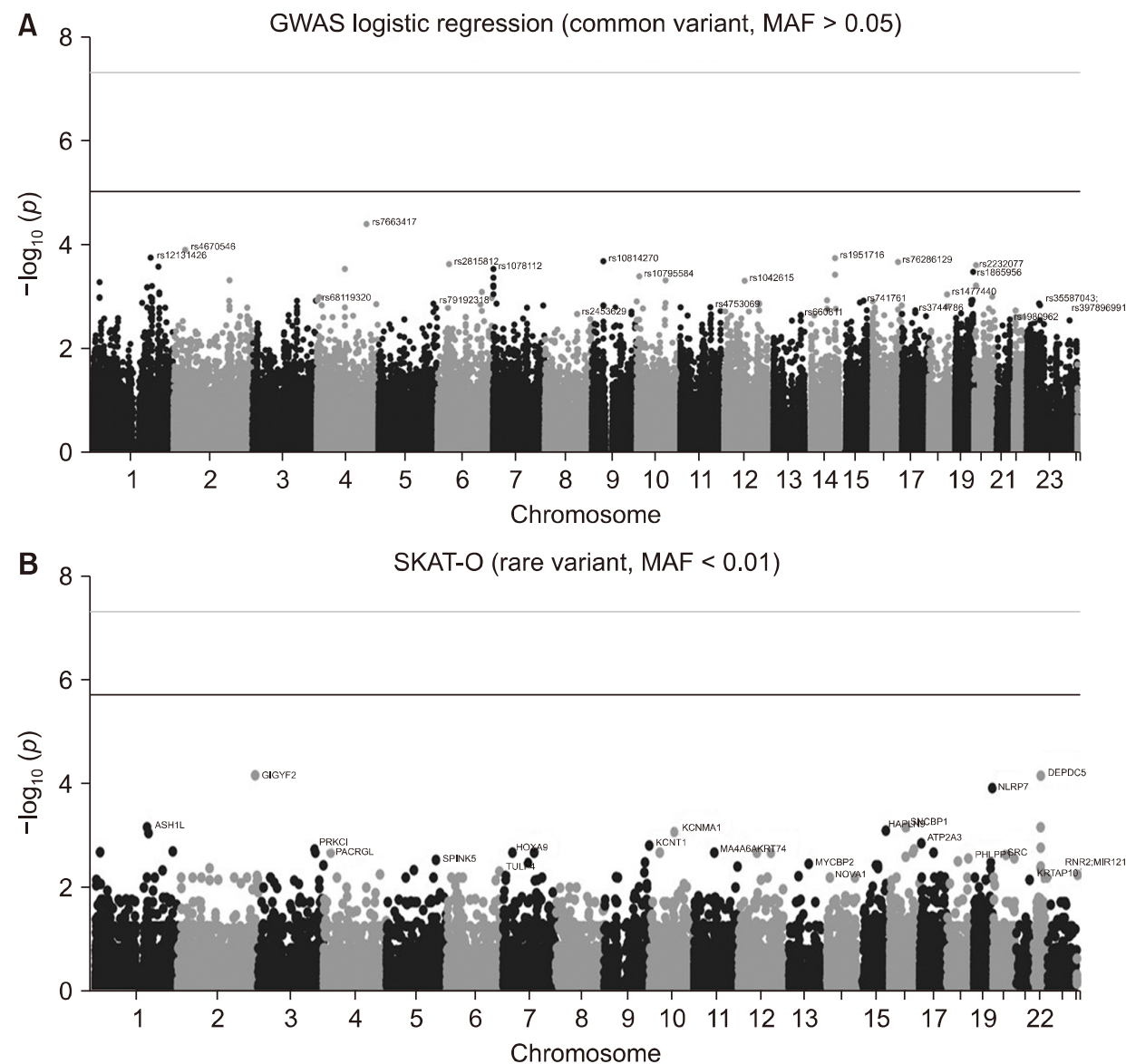

Fig. 2. Findings from analyses of PTS-related variants. (A) Manhattan plot for common variants in genome-wide association analyses. (B) Manhattan plot for rare variants in SKAT-O test. The negative logarithm of the association two-sided $p$ value from a logistic regression model for each common variants and from SKAT-O model for overlapping genes (gene setID) of each rare variants is reported on the $y$ axis. The light grey lines indicate the statistical significance using Bonferroni multiple-testing correction by $0.05 /$ numbers of analyzed common variants (0.05/23354) in (A) and by 0.05 /numbers of gene setID encompassing identified rare variants (0.05/23780) in (B). The black lines indicate the suggestive significance of $\mathrm{P}=5 \times$ $10^{-5}$.

PTS, posttraumatic syndrome; MAF, minor allele frequency; GWAS, genome-wide association study; SKAT-O, optimal sequencing kernel association test.

pathogenic variants in clinical databases, differences in disease prevalence, and differences in sample characteristics (e.g., community populations vs. case-control groups, confirmed vs. suspected disease).

The secondary findings were evaluated according to the PTS status immediately after severe physical injury. The number of secondary findings did not significantly differ by PTS status, but the pathways differed. GADD45 and aldosterone signaling were associated with secondary findings in the patients with PTS. Gadd45 genes have been implicated in signaling in response to physiological or environmental stressors, where such signaling is associated with cell cycle arrest, DNA repair, cell survival and senescence, and apoptosis $[44,60]$. Moreover, aldoster- one serves as a mediator of psychological stress because it is released in response to hypothalamus - pituitary adrenal (HPA) axis activation, which is the main stress system; activity therein increases oxidative stress and promotes proinflammatory reactions [61]. Our patients who experienced PTS after severe physical injury were more likely to have significant secondary findings in stress and inflammatory pathways, whereas patients who did not suffer from PTS had significant secondary findings in the glucose metabolism pathway. Genetic alterations in stress and inflammatory pathways might heighten stress and inflammatory responses to severe physical injury, and thus render patients vulnerable to PTS (because depression, anxiety, and ASD are pathophysiologically associated 
Table 3. Suggestive variants to post-traumatic stress syndrome at $p$ value $<0.001$

\begin{tabular}{|c|c|c|c|c|c|c|c|}
\hline Position & rsID & Altered allele & Gene & Location & Function & Odd ratio & $p$ value \\
\hline Chr1: 113973095 & rs2358996 & $G>A$ & HIPK1 & Coding sequence & Synonymous & 2.837 & 0.000161 \\
\hline Chr7: 89333725 & rs1916830 & $G>A$ & ZNF804B & Coding sequence & Missense & 2.969 & 0.000169 \\
\hline Chr7: 48410692 & rs62447268 & $C>G$ & $A B C A 13$ & Intron variant & & 3.394 & 0.000191 \\
\hline Chr7: 48412342 & rs1865195 & $\mathrm{T}>\mathrm{C}$ & $A B C A 13$ & Intron variant & & 3.394 & 0.000191 \\
\hline Chr7: 48412603 & rs7789493 & $G>A$ & $A B C A 13$ & Intron variant & & 3.394 & 0.000191 \\
\hline Chr5: 52927520 & rs923837 & $A>G$ & ITGA1 & Intron variant & & 0.319 & 0.000251 \\
\hline Chr7: 48410500 & rs62447267 & $\mathrm{C}>\mathrm{T}$ & $A B C A 13$ & Intron variant & & 3.078 & 0.000343 \\
\hline Chr5: 78839453 & rs25415 & $\mathrm{T}>\mathrm{G}$ & $A R S B$ & Intron variant & & 3.588 & 0.000531 \\
\hline Chr2: 191836667 & rs10167187 & $\mathrm{A}>\mathrm{T}$ & $S D P R$ & Coding sequence & Synonymous & 0.335 & 0.000534 \\
\hline Chr1: 203486626 & rs2233731 & $G>A$ & PRELP & Intron variant & & 4.450 & 0.000647 \\
\hline Chr5: 77413162 & rs335614 & $A>G$ & PDEBB & Coding sequence & Synonymous & 0.332 & 0.000655 \\
\hline Chr6: 116925413 & $\begin{array}{l}\text { rs1245948737; } \\
\text { rs398048786; } \\
\text { rs6729208 }\end{array}$ & Duplication & RFXG & Intron variant & & 0.402 & 0.000658 \\
\hline Chr2: 222201151 & rs3731858 & $C>G$ & $P A Z 3$ & 3 prime UTR variant & & 0.377 & 0.000729 \\
\hline Chr1: 203483098 & rs2233724 & $\mathrm{T}>\mathrm{C}$ & PRELP & Intron variant & & 0.360 & 0.000742 \\
\hline Chr2: 159742982 & rs75774925 & $A>G$ & MARCHT & Intron variant & & 0.179 & 0.000758 \\
\hline Chr6: 116916361 & rs1321372 & $G>A$ & RFX6 & Intron variant & Missense? & 0.405 & 0.000779 \\
\hline Chr1: 248387593 & rs7418152 & $\mathrm{T}>\mathrm{G}$ & & $2 \mathrm{~KB}$ upstream variant & Missense? & 0.399 & 0.00107 \\
\hline Chr1: 248387669 & rs7417616 & $A>G$ & OR2T6 & Coding sequence & Missense & 0.399 & 0.00107 \\
\hline Chr1: 248387902 & rs6700947 & $\mathrm{T}>\mathrm{C}$ & OR2T6 & Coding sequence & Synonymous & 0.399 & 0.00107 \\
\hline Chr1: 248388259 & rs954474 & $\mathrm{C}>\mathrm{T}$ & OR2T6 & Coding sequence & Missense? & 0.399 & 0.00107 \\
\hline
\end{tabular}

rsID, reference ID.

with inflammation and stress systems, such as the HPA axis) $[62,63]$. Genetic alterations in the glucose metabolism pathway might be less important immediately after physical injury, considering the low energy requirements associated with a bed-ridden state compared to the energy required for the performance of daily activities. Additionally, alterations in glucose metabolism could be related to a normal stress reaction rather than a disturbance in the inflammatory pathway, which is well-known to play a role in psychiatric distress [64].

Similar to previous GWAS studies [4,6] reporting no genome-wide significant findings due to a lack of power (small sample size) and non-replication of loci associated with PTSD, our WES analysis failed to identify genetic variants associated with PTS status. However, this is the first study to use WES to evaluate the genetic architecture underlying PTS occurring immediately after severe physical injury in a non-European population. Studies of PTS using larger, more ethnically diverse samples are needed to elucidate the genetic architecture of trauma-related psychiatric distress.

The present study had several strengths. First, the participants were consecutively recruited from among all eligible patients who had recently sustained a severe physical injury. This minimized the error associated with heterogeneous traumatic events and examination times after index traumatic events. Additionally, the presence of PTS symptoms, including depression, anxiety, and ASD, was evaluated using structured diagnostic interviews and validated measurements. However, several limitations should also be considered when interpreting our findings. First, the study used a single-center design and only recruited members of the Korean population; this limits the generalizability of the findings but is advantageous in terms of the consistency of the evaluations and genetic homogeneity. Moreover, there was a higher proportion of male patients $(65.2 \%)$ and PTS status was assessed only cross-sectionally. These contributed to negative associations because female sex bias in stress-related psychiatric disorders [65] and late-onset PTS [3] were not considered in the present analyses. Finally, variants outside protein-coding regions were not included in our analyses; this should be addressed in future studies.

In conclusion, although the genetic architecture of PTS occurring immediately after severe physical injury was not fully elucidated in this study, slight differences in secondary findings were found between PTS and non-PTS patients. Although the prevalence of secondary findings 
did not differ markedly by PTS status, the patients in the PTS group were more likely to have significant secondary findings in the stress and inflammatory pathways. To better identify the genetic variants associated with PTS status, a larger sample size and longitudinal study design will be needed.

\section{Acknowledgments}

The study was funded by a grant of National Research Foundation of Korea Grant (NRF-2020R1A2C2003472 [to JMK]), by a grant of National Research Foundation of Korea Grant (NRF-2017M3A9E8023015 [to HJK]), and by a grant of National Research Foundation of Korea Grant (2014M3C9A3064552 [to NK]) and by KRIBB initiative program.

\section{Conflicts of Interest}

No potential conflict of interest relevant to this article was reported.

\section{Author Contributions}

Conceptualization: Jae-Min Kim. Data acquisition: Hee-Ju Kang, Ju-Wan Kim, Jung-Chul Kim. Formal analysis: Hee-Ju Kang, Ho-Yeon Lee, Ki-Tae Kim, Namshin Kim. Supervision: Jae-Min Kim, Namshin Kim. Writingoriginal draft: Hee-Ju Kang, Ho-Yeon Lee. Writing-review \& editing: Jae-Min Kim, Ki-Tae Kim, Namshin Kim, Ju-Wan Kim, Jung-Chul Kim, Ju-Yeon Lee, Sung-Wan Kim, Il-Seon Shin.

\section{ORCID}

Hee-Ju Kang Ho-Yeon Lee https://orcid.org/0000-0002-4784-4820 Ki-Tae Kim https://orcid.org/0000-0002-1026-1744 Ju-Wan Kim https://orcid.org/0000-0002-5244-2092 Ju-Yeon Lee https://orcid.org/0000-0002-9888-1090 Sung-Wan Kim https://orcid.org/0000-0003-0653-7223 Jung-Chul Kim https://orcid.org/0000-0002-6739-2163 https://orcid.org/0000-0002-6774-1861 II-Seon Shin https://orcid.org/0000-0001-5370-7649 Namshin Kim https://orcid.org/0000-0001-6361-274X Jae-Min Kim https://orcid.org/0000-0001-7409-6306

\section{REFERENCES}

1. Schweininger S, Forbes D, Creamer M, McFarlane AC, Silove D, Bryant RA, et al. The temporal relationship between mental health and disability after injury. Depress Anxiety 2015;32:
64-71.

2. Lee K, Song HC, Choi EJ, Pae CU, Kim YK. Posttraumatic embitterment disorder in patients with chronic kidney disease. Clin Psychopharmacol Neurosci 2019;17:183-188.

3. Bryant RA, Nickerson A, Creamer M, O’Donnell M, Forbes D, Galatzer-Levy I, et al. Trajectory of post-traumatic stress following traumatic injury: 6-year follow-up. Br J Psychiatry 2015;206:417-423.

4. Sharma S, Ressler KJ. Genomic updates in understanding PTSD. Prog Neuropsychopharmacol Biol Psychiatry 2019; 90:197-203.

5. Yang S, Wynn GH, Ursano RJ. A clinician's guide to PTSD biomarkers and their potential future use. Focus (Am Psychiatr Publ) 2018;16:143-152.

6. Maul S, Giegling I, Fabbri C, Corponi F, Serretti A, Rujescu D. Genetics of resilience: implications from genome-wide association studies and candidate genes of the stress response system in posttraumatic stress disorder and depression. Am J Med Genet B Neuropsychiatr Genet 2020;183:77-94.

7. McFarlane AC. Posttraumatic stress disorder: a model of the longitudinal course and the role of risk factors. I Clin Psychiatry 2000;61 Supp/ 5:15-20.

8. Moon E, Lee SH, Kim DH, Hwang B. Comparative study of heart rate variability in patients with schizophrenia, bipolar disorder, post-traumatic stress disorder, or major depressive disorder. Clin Psychopharmacol Neurosci 2013;11:137-143.

9. Shalev AY, Peri T, Canetti L, Schreiber S. Predictors of PTSD in injured trauma survivors: a prospective study. Am J Psychiatry 1996; 153:219-225.

10. Pritchard JK, Cox NJ. The allelic architecture of human disease genes: common disease-common variant...or not? Hum Mol Genet 2002;11:2417-2423.

11. Lazaridis KN, Cheung AC. Whole exome sequencing leading to novel therapeutic discovery. Gastroenterology 2018;155. 1264-1265.

12. Manolio TA, Collins FS, Cox NJ, Goldstein DB, Hindorff LA, Hunter DJ, et al. Finding the missing heritability of complex diseases. Nature 2009;461:747-753.

13. Botstein D, Risch N. Discovering genotypes underlying human phenotypes: past successes for mendelian disease, future approaches for complex disease. Nat Genet 2003;33 Suppl: 228-237.

14. Kim JW, Kang HJ, Bae KY, Kim SW, Oh HK, Kim MG, et al. Development of a biomarker-based diagnostic algorithm for posttraumatic syndrome after physical injury: design of the BioPTS study. Psychiatry Investig 2017;14:513-517.

15. Baker SP, O'Neill B, Haddon W Jr, Long WB. The injury severity score: a method for describing patients with multiple injuries and evaluating emergency care. / Trauma 1974;14: 187-196.

16. American Psychiatric Association. Diagnostic and statistical manual of mental disorders: DSM-5. 5th ed. Arlington, VA:American Psychiatric Association;2013. 
17. Sheehan DV, Lecrubier $\mathrm{Y}$, Sheehan $\mathrm{KH}$, Amorim P, Janavs J, Weiller $\mathrm{E}$, et al. The Mini-International Neuropsychiatric Interview (M.I.N.I.): the development and validation of a structured diagnostic psychiatric interview for DSM-IV and ICD-10. J Clin Psychiatry 1998;59 Supp/ 20:22-33.

18. Weathers FW, Bovin MJ, Lee DJ, Sloan DM, Schnurr PP, Kaloupek DG, et al. The Clinician-Administered PTSD Scale for DSM-5 (CAPS-5): Development and initial psychometric evaluation in military Veterans. Psychol Assess 2018;30:383395.

19. Hamilton M. A rating scale for depression. J Neurol Neurosurg Psychiatry 1960;23:56-62.

20. Zigmond AS, Snaith RP. The hospital anxiety and depression scale. Acta Psychiatr Scand 1983;67:361-370.

21. Hamilton M. The assessment of anxiety states by rating. $\mathrm{Br} J$ Med Psychol 1959;32:50-55.

22. Weiss DS, Marmar CR. The impact of event scale, revised. In: Wilson JP, Keane TM, editors. Assessing psychological trauma and PTSD. New York:Guilford Press; 1997. p.399-411.

23. Li H, Durbin R. Fast and accurate short read alignment with Burrows-Wheeler transform. Bioinformatics 2009;25:17541760.

24. McKenna A, Hanna M, Banks E, Sivachenko A, Cibulskis K, Kernytsky A, et al. The Genome Analysis Toolkit: a MapReduce framework for analyzing next-generation DNA sequencing data. Genome Res 2010;20:1297-1303.

25. DePristo MA, Banks E, Poplin R, Garimella KV, Maguire JR, Hartl C, et al. A framework for variation discovery and genotyping using next-generation DNA sequencing data. Nat Genet 2011;43:491-498.

26. Lee S, Seo J, Park J, Nam JY, Choi A, Ignatius JS, et al. Korean Variant Archive (KOVA): a reference database of genetic variations in the Korean population. Sci Rep 2017;7:4287.

27. Kalia SS, Adelman K, Bale SJ, Chung WK, Eng C, Evans JP, et al. Recommendations for reporting of secondary findings in clinical exome and genome sequencing, 2016 update (ACMG SF v2.0): a policy statement of the American College of Medical Genetics and Genomics. Genet Med 2017;19: 249-255.

28. Landrum MJ, Lee JM, Riley GR, Jang W, Rubinstein WS, Church DM, et al. ClinVar: public archive of relationships among sequence variation and human phenotype. Nucleic Acids Res 2014;42(Database issue):D980-D985.

29. Stenson PD, Mort M, Ball EV, Evans K, Hayden M, Heywood $\mathrm{S}$, et al. The Human Gene Mutation Database: towards a comprehensive repository of inherited mutation data for medical research, genetic diagnosis and next-generation sequencing studies. Hum Genet 2017;136:665-677.

30. Krämer A, Green J, Pollard J Jr, Tugendreich S. Causal analysis approaches in Ingenuity Pathway Analysis. Bioinformatics 2014;30:523-530.

31. Lee $\mathrm{S}, \mathrm{Wu} \mathrm{MC}$, Lin X. Optimal tests for rare variant effects in sequencing association studies. Biostatistics 2012;13:762-775.
32. López-Colomé AM, Lee-Rivera I, Benavides-Hidalgo R, López E. Paxillin: a crossroad in pathological cell migration. J Hematol Oncol 2017;10:50.

33. Deakin NO, Turner CE. Paxillin comes of age. J Cell Sci 2008; 121(Pt 15):2435-2444.

34. Harburger DS, Calderwood DA. Integrin signalling at a glance. J Cell Sci 2009;122(Pt 2):159-163.

35. Lilja J, Ivaska J. Integrin activity in neuronal connectivity. J Cell Sci 2018;131:jcs212803.

36. Jaudon F, Thalhammer A, Cingolani LA. Integrin adhesion in brain assembly: from molecular structure to neuropsychiatric disorders. EurJ Neurosci 2020. doi: 10.1111/ejn. 14859. [Epub ahead of print]

37. Dudás A, Chovanec M. DNA double-strand break repair by homologous recombination. Mutat Res 2004;566:131-167.

38. Glaser JH, Conrad HE. Chondroitin SO4 catabolism in chick embryo chondrocytes. J Biol Chem 1979;254:2316-2325.

39. Trowbridge JM, Gallo RL. Dermatan sulfate: new functions from an old glycosaminoglycan. Glycobiology 2002;12: $117 R-125 R$

40. American Cancer Society. Breast Cancer Facts \& Figures 2019-2020. Atlanta:American Cancer Society, Inc.;2019.

41. Danilkovitch A, Leonard EJ. Kinases involved in MSP/RON signaling. J Leukoc Biol 1999;65:345-348.

42. Lu T, Wang Z, Prativa S, Xu Y, Wang T, Zhang Y, et al. Macrophage stimulating protein preserves blood brain barrier integrity after intracerebral hemorrhage through recepteur d'origine nantais dependent $G A B 1 / S r C / \beta$-catenin pathway activation in a mouse model. J Neurochem 2019;148:114-126.

43. Wilson CB, Ray M, Lutz M, Sharda D, Xu J, Hankey PA. The $R O N$ receptor tyrosine kinase regulates IFN-gamma production and responses in innate immunity. I Immunol 2008;181: 2303-2310.

44. Liebermann DA, Hoffman B. Gadd45 in stress signaling. J Mol Signal 2008;3:15.

45. Laronga C, Yang HY, Neal C, Lee MH. Association of the cyclin-dependent kinases and 14-3-3 sigma negatively regulates cell cycle progression. J Biol Chem 2000;275:23106-23112.

46. Yang H, Wen YY, Zhao R, Lin YL, Fournier K, Yang HY, et al. DNA damage-induced protein 14-3-3 sigma inhibits protein kinase B/Akt activation and suppresses Akt-activated cancer. Cancer Res 2006;66:3096-3105.

47. Gomez-Sanchez E, Gomez-Sanchez CE. The multifaceted mineralocorticoid receptor. Compr Physiol 2014;4:965-994.

48. Murck H, Schlageter L, Schneider A, Adolf C, Heinrich D, Quinkler M, et al. The potential pathophysiological role of aldosterone and the mineralocorticoid receptor in anxiety and depression - lessons from primary aldosteronism. J Psychiatr Res 2020;130:82-88.

49. Miki Y, Swensen J, Shattuck-Eidens D, Futreal PA, Harshman K, Tavtigian S, et al. A strong candidate for the breast and ovarian cancer susceptibility gene BRCA1. Science 1994;266:66-71.

50. Huen MS, Sy SM, Chen J. BRCA1 and its toolbox for the main- 
tenance of genome integrity. Nat Rev Mol Cell Biol 2010;11: 138-148.

51. Roy R, Chun J, Powell SN. BRCA1 and BRCA2: different roles in a common pathway of genome protection. Nat Rev Cancer 2011;12:68-78.

52. Berg JM, Tymoczko JL, Stryer L. Glycogen metabolism. In: Berg JM, Tymoczko IL, Stryer L, editors. Biochemistry. 5th ed. New York:W.H. Freeman;2002.

53. Dorschner MO, Amendola LM, Turner EH, Robertson PD, Shirts BH, Gallego CJ, et al. Actionable, pathogenic incidental findings in 1,000 participants' exomes. Am J Hum Genet 2013;93:631-640.

54. Amendola LM, Dorschner MO, Robertson PD, Salama JS, Hart $\mathrm{R}$, Shirts $\mathrm{BH}$, et al. Actionable exomic incidental findings in 6503 participants: challenges of variant classification. Genome Res 2015;25:305-315.

55. Green RC, Berg JS, Grody WW, Kalia SS, Korf BR, Martin CL, et al:; American College of Medical Genetics and Genomics. ACMG recommendations for reporting of incidental findings in clinical exome and genome sequencing. Genet Med 2013; 15:565-574.

56. Jurgens J, Ling $\mathrm{H}$, Hetrick $\mathrm{K}$, Pugh $\mathrm{E}$, Schiettecatte $\mathrm{F}$, Doheny $\mathrm{K}$, et al. Assessment of incidental findings in 232 whole-exome sequences from the Baylor-Hopkins Center for Mendelian Genomics. Genet Med 2015;17:782-788.

57. Jang MA, Lee SH, Kim N, Ki CS. Frequency and spectrum of actionable pathogenic secondary findings in 196 Korean exomes. Genet Med 2015;17:1007-1011.

58. Jamuar SS, Kuan JL, Brett M, Tiang Z, Tan WL, Lim JY, et al.
Incidentalome from genomic sequencing: a barrier to personalized medicine? EBioMedicine 2016:5:211-216.

59. Yamaguchi-Kabata Y, Yasuda J, Tanabe O, Suzuki Y, Kawame $\mathrm{H}$, Fuse $\mathrm{N}$, et al. Evaluation of reported pathogenic variants and their frequencies in a Japanese population based on a whole-genome reference panel of 2049 individuals. J Hum Genet 2018;63:213-230

60. Grassi D, Franz H, Vezzali R, Bovio P, Heidrich S, Dehghanian $\mathrm{F}$, et al. Neuronal activity, TGF $\beta$-signaling and unpredictable chronic stress modulate transcription of Gadd45 family members and DNA methylation in the hippocampus. Cereb Cortex 2017;27:4166-4181.

61. Kubzansky LD, Adler GK. Aldosterone: a forgotten mediator of the relationship between psychological stress and heart disease. Neurosci Biobehav Rev 2010;34:80-86.

62. Pariante CM. Why are depressed patients inflamed? A reflection on 20 years of research on depression, g/ucocorticoid resistance and inflammation. Eur Neuropsychopharmacol 2017:27:554-559.

63. Fabbri C, Serretti A. Genetics of treatment outcomes in major depressive disorder: present and future. Clin Psychopharmacol Neurosci 2020;18:1-9.

64. Miller $\mathrm{AH}$, Raison $\mathrm{CL}$. The role of inflammation in depression: from evolutionary imperative to modern treatment target. Nat Rev Immunol 2016;16:22-34.

65. Nievergelt CM, Ashley-Koch AE, Dalvie S, Hauser MA, Morey RA, Smith AK, et al. Genomic approaches to posttraumatic stress disorder: the psychiatric genomic consortium initiative. Biol Psychiatry 2018;83:831-839. 